\title{
Freud E A FILOGENiA ANÍMiCA ${ }^{\star}$
}

Monah Winograd ${ }^{\star}$

\begin{abstract}
Resumo
Este ensaio investiga a presença, na obra de Freud, da idéia de uma filogenia anímica paralela, concomitante e dependente da filogenia somática descrita pelos teóricos da evolução. Objetivamos mostrar como se forma esta vizinhança da psicanálise com a biologia evolutiva, sublinhando que na filogenia esboçada por Freud, formas psíquicas típicas se sucedem na história da espécie humana, sendo repetidas por cada indivíduo em sua ontogenia singular. Tal como ocorre no plano somático, tempo e forma se associam intimamente na espécie e nos indivíduos. A presença desta idéia no pensamento freudiano abriu um debate sobre sua filiação lamarckista ou darwinista.
\end{abstract}

Palavras-chave: Freud. Filogenia. Evolução. Ontogenia.

\section{FREUd AND THE ANIMIC PHYLOGENY}

\begin{abstract}
This essay investigates the presence, in Freud's work, of the idea of an animic phylogeny parallel, concomitant and dependent of the somatic phylogeny that the theoreticians of evolution describe. Our objective is to show how this neighborhood between psychoanalysis and evolutionary theory is formed. To do so, we stress that, in the phylogeny theory that Freud sketches, typical psychic forms occurs in the history of the human kind in a way that each individual repeats it in its singular ontogeny. As it happens in the somatic level, time and form are intimately associated in the species and in the individuals. The presence of that idea in Freud's work has opened a debate about his Darwinist or Lamarckist inspiration.
\end{abstract}

Keywords: Freud. Phylogeny. Evolution. Ontogeny.

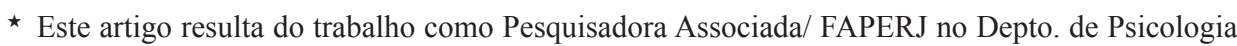
da PUC-Rio.

$\star \star$ Psicanalista, Doutora em Teoria Psicanalítica (UFRJ), Pesquisadora Associada do Departamento de Psicologia Clínica da PUC-Rio/ FAPERJ, autora do livro Genealogia do sujeito freudiano, Artmed, 1998. Endereço: PUC-Rio, Departamento de Psicologia, Av. Marquês de São Vicente, 225/Prédio Leme, $20^{\circ}$ andar, Gávea, Rio de Janeiro/RJ, CEP 22453-900.

e-mail: winograd@uol.com.br 
"O quanto à disposição filogenética pode contribuir para a compreensão das neuroses, não podemos ainda estimar" (FREUD, 1987, p.10), escreve Freud num rascunho datado de 1915 e encontrado em 1983, Panorama das neuroses de transferência. "É ainda legítimo admitir que as neuroses devem também dar testemunho da história do desenvolvimento anímico do ser humano", prossegue antes de acrescentar que

[...] tem-se aqui a impressão de que a história do desenvolvimento da libido recapitula uma porção muito mais antiga do desenvolvimento filogenético do que aquela do eu; a primeira repete talvez as condições de vida da genealogia dos vertebrados, enquanto a última é dependente da história da espécie humana (FREUD, 1987, p. 11-12).

Sandor Ferenczi (1873-1933) - dentre os que circundavam Freud, o mais tentado pela pesquisa de analogias recíprocas entre fatos biológicos e fatos psicológicos - está constantemente presente nas notas deixadas por Freud neste manuscrito não publicado. Sabe-se que em 1917 eles formaram em conjunto o projeto não realizado de um trabalho de inspiração lamarckista, visando a esclarecer as relações entre Psicanálise e Teoria da Evolução. Apesar desta parceria inicial, em 1924, Ferenczi assinará sozinho seu Thalassa, ensaio sobre a teoria da genitalidade, no qual relaciona ontogênese e filogênese e cria o que chamou de bioanálise.

Em seu livro, as catástrofes geográficas que determinaram a evolução da espécie humana, sobretudo a catástrofe da emergência dos continentes, são relacionadas ao desenvolvimento psíquico do ser humano, conforme o quadro abaixo (FERENCZI, 1990, p. 86):

\begin{tabular}{|c|c|c|}
\hline & Filogenia & Ontogenia \\
\hline Catástrofe I & Aparecimento da vida orgânica & $\begin{array}{l}\text { Maturação das células } \\
\text { sexuais }\end{array}$ \\
\hline Catástrofe II & $\begin{array}{l}\text { Aparecimento dos organismos } \\
\text { unicelulares individuais }\end{array}$ & $\begin{array}{l}\text { "Nascimento" das células } \\
\text { germinais maduras nas } \\
\text { gônadas }\end{array}$ \\
\hline Catástrofe III & $\begin{array}{l}\text { Início da reprodução sexuada } \\
\text { Desenvolvimento da vida } \\
\text { marinha }\end{array}$ & $\begin{array}{l}\text { Fecundação } \\
\text { Desenvolvimento do } \\
\text { embrião no útero materno }\end{array}$ \\
\hline Catástrofe IV & $\begin{array}{l}\text { Secagem do oceano, adaptação à } \\
\text { vida terrestre } \\
\text { Aparecimento de espécies } \\
\text { animais dotadas de órgãos } \\
\text { genitais }\end{array}$ & $\begin{array}{l}\text { Nascimento } \\
\text { Desenvolvimento do } \\
\text { primado da zona genital }\end{array}$ \\
\hline Catástrofe $\mathbf{V}$ & $\begin{array}{l}\text { Era glacial, hominização } \\
\text { progressiva }\end{array}$ & Período de latência \\
\hline
\end{tabular}


Na clínica, se o analista dispuser dos meios para imaginar analogicamente o que ele escuta de seus pacientes, uma sessão pode equivaler a uma seqüência ontogenética que recapitula a infância filogenética da espécie no indivíduo (FÉDIDA, 1994; PINHEIRO, 1995).

As reticências de Freud não o impediram de ter admiração pelas intuições de Ferenczi, mas o modo como entendia os limites da psicanálise o fazia severamente crítico com relação a todo projeto de extensão desta para uma bioanálise e da metapsicologia para uma metabiologia. Na última página do famoso caso do homem dos lobos, Freud (1993a, p. 109-110) adverte:

Sei que diversos autores formularam idéias parecidas que destacam o fator hereditário, filogeneticamente adquirido, na vida anímica; e ainda considero que se estava demasiado propenso a outorgar-lhes um lugar dentro da apreciação psicanalítica. Tais fatores só me parecem admissíveis quando a psicanálise, obedecendo ao itinerário correto de instâncias, cai sobre a pista do herdado, depois de irromper pelo estrato do adquirido individualmente.

Além, é claro, do fato de que, por mais que fosse possível e sedutor tentar imaginar por inferência aspectos da história do desenvolvimento do eu e do desenvolvimento da libido na espécie humana a partir do que a psicanálise permitia observar, era preciso ter cautela na utilização destas hipóteses. Para Freud, a solução de alguns problemas precisava dos esforços de outros campos de pesquisa.

Mesmo com estas ressalvas prévias, Freud compartilhava as intuições catastrófico-evolutivas de Ferenczi e, em 1915, the enviou o tal rascunho citado acima. Em 1913, o médico húngaro publicou um artigo sobre "O desenvolvimento do sentido de realidade e seus estágios", no qual arriscou a hipótese de que "[...] foram as modificações geológicas da crosta terrestre, e suas conseqüências catastróficas para os ancestrais da espécie humana, que forçaram o recalcamento dos hábitos preferidos e abriram caminho para a "evolução"” (FERENCZI, 1993, p. 52). Freud modulou esta hipótese e propôs que o desenvolvimento do homem originário teria se "[...] efetuado sob a influência dos destinos geológicos da Terra, e que, em particular, as exigências da Idade do Gelo lhe trouxeram a incitação para o desenvolvimento da civilização" (FREUD, 1987, p.13). Com efeito, o metapsicólogo se mostrou bastante tentado a:

[...] reconhecer nas três disposições para a histeria de angústia, histeria de conversão e neurose obsessiva, regressões a fases pelas quais toda a espécie humana teve que passar em algum momento, do início ao fim dos tempos glaciais, de modo que todos os seres humanos eram como apenas alguns são hoje, em virtude de sua tendência hereditária e por neo-aquisição. (FREUD, 1987, p.13)

A neurose obsessiva testemunha, evidentemente, um tempo do desenvolvimento no qual a linguagem e o pensamento são progressos assegurados sobre o estágio anterior. A histeria de conversão, por sua vez, seria um retorno do eu a uma 
fase sem separação entre Pré-consciente e Inconsciente, portanto sem linguagem nem censura. A histeria de angústia remontaria a uma fase mais antiga, expressando um modo de reação ainda mais primário às intempéries.

Este rascunho - do qual Freud sequer guardou cópia para si, deixando ao destinatário a decisão sobre sua importância (GUBRICH-SIMITIS, 1987) - mostra bem o outro pressuposto, nem sempre explícito, que está na base do seu modo de pensar o psíquico. Se o paralelismo psicofísico marcava seu entendimento das relações entre a alma e o órgão de sua atividade, o cérebro, o evolucionismo permeia sua compreensão do devir anímico no tempo. Como qualquer médico que se graduasse na Viena fin-de-siècle, ele tinha a Teoria da Evolução em sua formação básica. Tinha também, em seu currículo, um trabalho publicado em 1877, Observações sobre a conformação do órgão lobuloso da lampréia, descrito como glândula germinal masculina, no qual prestava importante contribuição para o assunto.

Este tinha sido seu primeiro trabalho no laboratório de Ernst Brücke, onde estudou fisiologia nervosa de 1876 até 1882 . Era sobre a histologia do sistema nervoso, mais especificamente, sobre a histologia de uma forma peculiar de células nervosas descobertas numa espécie de peixe, o Petromyzon ou, para os leigos, a lampréia. Sabia-se, até então, que os animais vertebrados inferiores apresentavam células bipolares (possuidoras de dois processos) no gânglio espinhal, ao passo que os animais vertebrados superiores tinham células unipolares. As pesquisas do jovem Freud levaram-no à conclusão de que as células do Petromyzon constituíam uma espécie de células intermediárias.

Nos anos 1870, a teoria da seleção natural mantinha-se bastante controversa. Charles Robert Darwin (1809-1882) situara o homem no reino animal, arriscando-se a explicar seu surgimento, sobrevivência e desenvolvimento diferenciado. As causas que operavam nas transformações na ordem natural dos seres vivos não eram mais remetidas a uma divindade, mas expressavam a luta entre o organismo e seu meio, através dos tempos e das catástrofes (JACOB, 1983). O jovem Freud, estudioso das células do sistema nervoso, estava plenamente empenhado em participar deste novo modo de conceber a história natural, ao qual foi apresentado por Carl Claus (1835-1899), seu professor de evolucionismo. Suas descobertas histológicas comprovavam processos evolutivos e faziam com que uma lacuna na teoria da evolução fosse preenchida. As células intermediárias do Petromyzon revelavam o modo como se deu o trajeto evolutivo dos vertebrados inferiores aos vertebrados superiores. Através da demonstração de que o sistema nervoso dos animais inferiores e superiores é composto por elementos idênticos, a continuidade entre as espécies poderia ser estabelecida. Freud aderia às idéias de Darwin e participava dos esforços para demonstrar os caminhos da evolução. Porém, seu darwinismo não o impediu de fazer uso de outras teorias evolutivas, o que custou críticas severas à sua psicanálise.

O mundo de língua germânica conheceu a teoria darwinista da evolução sobretudo pelas palavras de Ernst H. Haeckel (1834-1919), biólogo e naturalista alemão que abraçou as idéias de Darwin, fazendo-se seu tradutor e predicador. Sendo impossível traduzir e predicar de modo completamente neutro, Haeckel 
acrescentou novas construções à teoria da evolução de Darwin. Dentre elas, a mais notória, inclusive entre não-biólogos, é conhecida sob o nome de "Lei biogenética fundamental". ${ }^{1}$ Segundo esta lei, a ontogênese recapitula a filogênese, ou seja, o pequenino vertebrado "o mais evoluído", no curso de seu desenvolvimento embrionário, repassa por todos os estágios de seus ancestrais filogenéticos.

Alain Prochianz (1994) ensina que, mesmo considerada cientificamente falsa, a contribuição intelectual de Haeckel foi importante por dois motivos. O primeiro é que, em sua concepção, o desenvolvimento embrionário das diferentes espécies se tornou uma prova da teoria da evolução de Darwin. Se cada ser vivo, em sua embriogênese, repete o desenvolvimento da sua espécie, então, cada desenvolvimento embrionário comprova as hipóteses sobre o que teria acontecido à espécie através dos tempos. O segundo motivo - e o mais importante para nós - é Haeckel ter formulado explicitamente a ligação entre a evolução das formas no desenvolvimento embrionário e no curso da evolução das espécies. Para o naturalista alemão, deveria haver um mecanismo comum que pudesse explicar as evoluções tanto dos indivíduos, quanto das espécies. Para Freud, também. Apenas, as formas consideradas pela psicanálise serão as anímicas e não as biológicas. Como explicar a gênese das formas anímicas e suas variações? Ou seja, como o psiquismo chegou à organização que chegou, quais os tipos que se pode encontrar e por que estes e não outros? Tempo e forma estão, para um Freud profundamente marcado pelo evolucionismo, estreitamente associados tanto na história da espécie humana, quanto nos processos de individuação (anímica, evidentemente).

A noção de evolução é bastante fluida. Tanto pode significar a própria vida (com suas etapas: nascimento, desenvolvimento, decadência), quanto se confunde com a idéia de progresso ou é identificada a uma potência criadora. Seja como for, nos três casos, a evolução está estreitamente associada com uma temporalidade. Segundo a Teoria da Evolução, ela pode ser resumida da seguinte maneira: todos os seres vivos são o resultado de uma longa série de transformações que conduziram à aparição e à diversificação das espécies por filiação a partir das formas de vida elementares. Noutras palavras, a evolução é a continuidade dos seres vivos numa dessemelhança orientada. Compartilhando desta noção de evolução, Freud acreditava que, assim como era possível traçar uma história da biologia da espécie humana através dos tempos, também deveria ser possível construir um histórico das formas anímicas, vislumbrando a herança deixada pelas organizações psíquicas ancestrais. Para tanto, contudo, ele contava com a biologia evolutiva, mesmo sabendo que a constituição do psiquismo não pode ser reduzida à suposta evolução linear biológica.

W. M. Wheeler, biólogo e pesquisador de insetos sociais do início do século XX, simpatizava com a psicanálise e ria de suas piadas. Em 1917, no discurso "Sobre os instintos", escreveu:

Depois de examinar, durante os últimos vinte anos, uma pequena biblioteca de psicologias água-com-açúcar de tipo acadêmico e perceber como seus autores ignoram ou simplesmente fazem alusão à existência de fenômenos 
biológicos estupendos e fundamentais como os da fome, do sexo e do medo, não devo discordar com, digamos, uma crítica imaginária chegada recentemente de Marte, que expressa a opinião de que muitos destes trabalhos aparentam ter sido feitos por seres nascidos e criados num campanário, castrados na sua tenra infância e alimentados continuamente por cinqüenta anos através de um tubo com um fluxo de nutrientes líquidos de composição química constante. (WHEELER, 1917 apud GOULD, 1977, p. 155)

Em meio aos seus louvores aos "marcianos", pode-se notar, contudo, um constrangimento cautelar. Wheeler (1917 apud GOULD, 1977, p. 156) achava que Freud talvez estivesse pedindo demais da biologia evolutiva: "Em nada é melhor vista a coragem da psicanálise do que no seu uso da lei biogenética. Eles certamente empregam este grande slogan biológico do século dezenove com uma intrepidez que faria o tímido biólogo do século vinte perder o fôlego". O que Wheeler não percebia era a diferença entre a recapitulação haeckeliana das morfologias ancestrais e a recapitulação mental das idéias e das condutas suposta por Freud. Noutras palavras, a diferença entre uma filogênese biológica dos corpos e uma filogênese anímica que ocorre ao mesmo tempo, em paralelo e numa relação de ação recíproca com a primeira. Diferença fundamental, pois era um dos argumentos centrais da teoria freudiana.

As recapitulações físicas são estágios transitórios substituídos pelas formas subseqüentes. No curso da evolução, uma determinada forma física dá lugar à outra. Os estágios mentais, ao contrário, podem coexistir: um estágio antigo não precisa desaparecer para dar lugar a um novo. $\mathrm{O}$ "infantil" continua habitando a alma adulta, assim como o "mais civilizado" continua "selvagem". O psíquico dispõe, enfim, de uma plasticidade que a matéria viva não possui, por mais diferenciada que seja:

Os desenvolvimentos da alma possuem uma peculiaridade que não se encontra em nenhum outro processo de desenvolvimento. Quando uma aldeia cresce até se converter em cidade, ou uma criança se torna um homem, aldeia e criança desaparecem na cidade ou no homem. Só a lembrança pode figurar novamente os antigos traços na imagem nova; na realidade, os antigos materiais ou formas foram abandonados e substituídos por novos. No desenvolvimento anímico, as coisas ocorrem diversamente. Aqui, a situação não é comparável com aquela, e não pode ser descrita a não ser asseverando que todo estágio evolutivo anterior se conserva junto aos mais tardios, deles derivados; a sucessão também envolve a coexistência, embora os materiais nos quais transcorre toda a série de transformações sejam os mesmos. Por mais que o estado anímico anterior não tenha se exteriorizado durante anos, tão certo é que subsiste, que um dia pode converter-se de novo na forma de manifestação das forças da alma, e, na realidade, na única forma, como se todos 
os desenvolvimentos mais tardios tivessem sido anulados, tivessem involuído. Esta plasticidade extraordinária dos desenvolvimentos da alma não é restrita quanto a sua direção; pode-se designá-la como uma capacidade particular para a involução — para a regressão — , pois pode ocorrer que, se uma etapa posterior e mais elevada de desenvolvimento é abandonada, não se possa alcança-la de novo. Contudo, os estágios primitivos sempre podem se restabelecer; o anímico primitivo é imperecível no sentido mais pleno. (FREUD, 1993e, p. 286-287)

Eis o pilar da filogenética freudiana que organiza todo o resto e permite a formulação de suas hipóteses, por mais fantasiosas que pareçam. Em O Mal-estar na cultura (1930), Freud oferece uma metáfora gráfica desta idéia: imaginemos a Roma moderna com todas as suas construções perfeitamente preservadas desde os dias de Rômulo até hoje. Logicamente, isto é impossível, pois dois objetos materiais não podem ocupar o mesmo lugar ao mesmo tempo. Mas, os processos psíquicos podem corresponder a esta visão de uma cidade verdadeiramente eterna: "[...] semelhante conservação de todos os estágios anteriores junto à forma última só é possível no anímico, e não estamos em condições de obter uma imagem perceptível desse fato." (FREUD, 1993b, p. 72). No psiquismo, o passado, via de regra, persevera: a sucessão envolve a coexistência.

De certo modo, ao pontuar o fato de que, no anímico, estágios precedentes estão presentes no estágio atual, Freud propunha que a dimensão temporal relativamente ao psíquico precisava ser diversa da implícita na Teoria da Evolução. Para pensar a evolução biológica e o desenvolvimento dos corpos, o evolucionismo operava com o tempo linear cronológico: de antes para depois e do menos perfeito para o mais perfeito. Por sua vez, Freud considerava o tempo do agora, do instante em que o psíquico acontece. Nele, as formas anteriores estão presentes, explícita ou implicitamente. $\mathrm{E}$ isto tanto filo, quanto ontogeneticamente: no anímico, o tempo opera de modo não-linear, é espiralado e pontual. Neste tempo, a evolução não se daria em direção à perfeição, mas, sim, no sentido de um desdobramento conforme o contexto e a história. Desdobramento no qual os momentos anteriores não se apagam completamente, pois deixam marcas que, eventualmente, podem permitir a sua (re)construção e que, sobretudo, determinam as formas que surgem no presente.

Destes "estágios anímicos anteriores", Freud acreditava ter encontrado, nas palavras de Pierre Fédida (1994), fósseis. Em 1900, anunciou sua intenção:

O sonhar, em seu conjunto, é uma regressão à condição mais primitiva do sonhador, uma reanimação de sua infância, das moções pulsionais que então o governavam e dos modos de expressão de que dispunha. Por trás desta infância individual, se nos promete alcançar uma perspectiva sobre a infância filogenética, sobre o desenvolvimento do gênero humano, do qual o do indivíduo é, de fato, uma repetição abreviada, influenciada pelas circunstâncias contingentes de sua vida. (FREUD, 1993c, p. 542) 
E, depois de citar Nietzsche ("no sonho 'segue em ação uma antiqüíssima relíquia do humano que agora já não pode ser alcançada por um caminho direto"'), Freud prossegue:

[...] isso nos leva a esperar que mediante a análise dos sonhos obteremos o conhecimento da herança arcaica do homem, o que há de inato em sua alma. Parece que os sonhos e as neuroses conservaram, para nós, da Antigüidade da alma, mais do que poderíamos supor, de modo que a psicanálise pode reclamar para si um lugar de destaque entre as ciências que se esforçam em reconstruir as fases mais antigas e obscuras dos começos da humanidade. (FREUD, 1993c, p. 542)

Treza anos depois, o metapsicólogo levou esta conviç̧ão às últimas conseqüências e embarcou num projeto evolucionista-antropológico ambicioso: descrever o que os sonhos e as neuroses lhe faziam ver da história do desenvolvimento anímico da humanidade, a saber, a passagem do estado de natureza para a civilização e, nessa passagem, as origens da regulação sexual mais comum entre os homens, o tabu do incesto. Aqui, mais do que no rascunho de 1915, sua idéia de uma filogênese anímica ganha visibilidade, pois Freud arrisca, mesmo hesitante, a contar publicamente uma versão psicanalítica da história da humanidade. Antes, porém, de apresentar a hipótese da horda primitiva e do assassinato do Pai também primevo, o metapsicólogo fez questão de esclarecer suas intenções com esta empreitada, dimensionando seu trabalho:

[os quatro ensaios que compõem o livro Totem e Tabu] devem conformar-se, pois, em suscitar atenção num e noutro campo [psicanálise, etnologia, lingüística, antropologia] e em despertar a expectativa de que intercâmbios mais freqüentes entre os especialistas resultarão indubitavelmente fecundos para a investigação. (FREUD, 1993g, p. 7)

Eram apenas hipóteses das quais, diga-se de passagem, Freud gostava o suficiente para referir-se a elas muitas outras vezes até o final de sua vida.

Gostava também de argumentar que o desenvolvimento libidinal geral dos indivíduos recapitula uma seqüência de estágios da história da civilização. Vestindo-se de antropólogo, comparava o narcisismo das crianças pequenas à crença primitiva na personificação e no poder dos pensamentos (animismo), o vínculo sexual com os pais (complexo edípico) ao desenvolvimento da religião monoteísta, e o domínio maduro do princípio de realidade à fase científica da civilização.

Se nos fosse permitido ver na demonstração da onipotência dos pensamentos entre os primitivos um testemunho do narcisismo, poderíamos atrever-nos a comparar os estágios do desenvolvimento da cosmovisão humana com as etapas do desenvolvimento libidinal do indivíduo. Então, tanto no tempo, quanto em seu conteúdo, a fase animista corresponderia ao narcisismo, a religiosa àquele grau de escolha de objeto que se caracteriza pela ligação com os pais, 
e a fase científica teria seu correspondente pleno no estado de maturidade do indivíduo que renunciou ao princípio de prazer e, sob a adaptação à realidade, busca seu objeto no mundo exterior. (FREUD, 1993g, p. 93)

Ele queria entender a gênese e as variações das formas anímicas que a psicanálise fazia ver. ${ }^{2}$ Formas anímicas necessariamente determinadas pelas formas corporais, ainda que apenas em parte. Para Freud, como vimos, os mecanismos que explicavam as segundas deveriam poder explicar pelo menos parte das primeiras, guardada a diferença fundamental entre as duas, a saber, a atualidade de estados anímicos passados.

Além da lei biogenética fundamental de Haeckel, Freud também recorreu à teoria da herança dos caracteres adquiridos, formulada por Jean-Baptiste Lamarck (1744-1829) e compartilhada por Haeckel.

Numa meditação mais cuidadosa, não podemos senão confessar que há tempos nos comportamos como se a herança de traços mnêmicos do que foi vivenciado pelos antepassados, independentemente de sua comunicação direta ou do influxo da educação pelo exemplo, estivesse fora de questão. Quando falamos da persistência de uma tradição antiga num povo, da formação do caráter de um povo, na maioria das vezes temos em mente uma tradição assim, herdada, e não uma que se propague por comunicação. Ou, ao menos, não distinguimos entre ambas e não nos demos conta da temeridade que cometemos com tal descuido. Afinal, nossa situação é dificultada pela atitude presente da ciência biológica, que não quer saber nada da herança, nos descendentes, de uns caracteres adquiridos. Nós, do nosso lado, com toda modéstia confessamos que, todavia, não podemos prescindir deste fator no desenvolvimento biológico. É certo que não se trata do mesmo nos dois casos: num, são caracteres adquiridos difíceis de apreender; no outro, são traços mnêmicos de impressões exteriores, algo de certo modo tangível. Mas, por acaso aconteça que não possamos representarmo-nos um sem o outro. (FREUD, 1993f, p. 96)

Por causa de declarações como essa, a teoria freudiana foi alvo de discussões acaloradas. De um lado, estudiosos, como Lucille B. Ritvo (1992), defenderam o darwinismo de Freud, afirmando que supô-lo lamarckista é um equívoco, se não um exagero tanto histórico, quanto bibliográfico. Prova disso é a ausência de referências nominais a Lamarck em seus textos publicados em vida. A única exceção é um trabalho de 1884 sobre a cocaína, Über Coca, no qual Freud menciona Lamarck a respeito deste mesmo assunto. Além desta, as únicas outras menções ao trabalho do naturalista francês estão na correspondência com Ferenczi, Abraham e Groddeck. Menções suficientemente importantes para levarem autores, como Frank J. Sulloway (1979), a considerarem Freud um psicolamarckista convicto. 
O lamarckismo, darwinismo ou haeckelismo de Freud é, na verdade, uma discussão enraizada no problema mais vasto e complexo da cientificidade da psicanálise. As provas de sua adesão a um ou outro ponto de vista valem, para alguns críticos ou defensores, como evidências da falsidade ou veracidade da teoria psicanalítica, segundo os modelos científicos dominantes. Evidentemente, o próprio Freud se preocupava profundamente com isso, pois pretendia inserir sua teoria no quadro mais vasto e mais geral das ciências. Daí sua preocupação em justificar um certo tom teleológico presente em algumas de suas teorias.

A diferença fundamental entre Lamarck e Darwin era justamente a adesão do inglês a um princípio não teleológico de seleção natural, em contraste com a crença de Lamarck numa visão teleológica do processo evolutivo (SLAVIN; KRIEGMAN, 1992). Para Darwin, a força criativa era a "variação" (jamais plenamente entendida por ele) em interação com a "seleção natural". Das duas, a seleção natural era seu foco: o meio determinava o sucesso do organismo e selecionava os tipos que poderiam reproduzir-se e garantir minimamente a sobrevida das proles. Esta concepção da seleção natural como uma força que enforma e modela era o grande diferencial entre a visão não-teleológica de Darwin e a visão teleológica de Lamarck.

Tanto o argumento funcional-adaptativo de Darwin, quanto o argumento teleológico de Lamarck, pretendiam explicar a enorme diversidade da vida e a adaptação das espécies ao seu meio. Tomemos o exemplo dos pássaros da espécie dos fringilídeos (azulões, canários, coleiros, bicudos, curiós, pintassilgos, tico-ticos, cardeais etc.). Uma explicação teleológica assumiria que, porque certos fringilídeos precisavam de bicos mais longos e pontudos, eles próprios foram capazes de gerar esta variação. O pressuposto é que toda forma de vida busca uma adequação pré-ordenada, ideal e a priori com o meio. Numa explicação funcional-adaptativa, o bico longo e pontudo teria presumidamente surgido a partir de uma variação genética em seu tamanho e em sua forma e teria sido favorecido pela seleção natural porque serviria à sua função melhor do que outras formas.

Como Darwin, Freud produzia argumentos funcionais-adaptativos, mas temia derrapar numa teleologia justamente porque utilizava a noção lamarckista da herança dos caracteres adquiridos (SLAVIN; KRIEGMAN, 1992). Talvez não haja melhor exemplo de seu temor do que quando, ao discutir a natureza da oralidade infantil (prazeres da sucção), hipotetizou que as crianças estão equipadas inatamente para se sentirem motivadas pelo prazer de sugar porque sugar é diretamente vantajoso para sua sobrevivência:

A meta sexual da pulsão infantil consiste em produzir a satisfação mediante a estimulação apropriada da zona erógena que, de um modo ou de outro, foi escolhida. Para que se crie uma necessidade de repeti-la, esta satisfação tem que ter sido vivenciada antes; e é lícito pensar que a natureza terá tomado medidas seguras para que esta vivência não tenha sido deixada ao acaso (FREUD, 1993h, p.167). 
Numa nota de rodapé acrescentada em 1920, Freud praticamente se desculpa pelo tom teleológico de suas afirmações. Talvez ele confundisse seu argumento funcional-adaptativo sobre as vantagens do prazer oral inato implicado no sugar com o que ele sabia estar associado com o lamarckismo (a herança dos caracteres adquiridos).

É claro que a seleção natural opera segundo certas regras supostas: o que é selecionado é o que "funciona", o que está "adaptado" ou o que se "adequa" com o meio. Mas, a seleção natural não opera randomicamente. Os atributos das espécies não foram, como Freud bem notou, "deixados ao acaso". Quando ele usa frases como "a natureza terá tomado medidas seguras", claramente supõe que pressões variadas operaram para modelar o psiquismo através de caminhos mais vantajosos para a sobrevivência dos indivíduos e da espécie humana através dos tempos. Por exemplo, no caso de um dos mecanismos psíquicos do esquecimento, o recalque, Freud afirma, numa passagem controversa, que seus diques (vergonha, nojo e moralidade) podem, chegado o caso, produzir-se espontaneamente, "[...] sem nenhuma ajuda da educação" (FREUD, 1993h, p. 161).

Seu raciocínio ia, como ensinou Darwin, da constatação das formas anímicas (mecanismos, organização e dinâmica) atuais às hipóteses sobre sua filogenia, do indivíduo à espécie do ponto de vista de uma memória histórica. A produção espontânea do mecanismo do recalque num indivíduo significava, por exemplo, que ele teria sido importante para a perseverança da espécie humana no tempo e, portanto, que o próprio mecanismo perseverou, encontrando uma inscrição orgânica. ${ }^{3}$ E não que, numa origem mítica, ele estivesse previsto como modo ideal de adequação dos humanos ao seu meio ou como um dos elementos de uma forma anímica humana preexistente para a qual a filogenia da espécie tenderia.

Por outro lado, é bem verdade que, subjetivamente, o recalque não engendra o melhor dos mundos. Mas, se os sintomas dele derivados sideram a vida anímica no conflito que se mantém atual, quem discordaria de que eles também são uma forma de adaptação ao meio, ou seja, modos que os indivíduos encontram para resistir psiquicamente às exigências da vida? ${ }^{4}$ Por mais ganhos que um sintoma neurótico possa trazer, sem sua formação o colapso talvez fosse inevitável.

Mas, o que determina a formação sintomática ou, o que é quase a mesma coisa, a escolha de neurose? Em termos mais genéricos, o que determina uma forma anímica, neurótica ou não? Para Freud, a filogênese anímica e a filogênese biológica trabalham juntas no que ele chama de fatores constitucionais. Na constituição do psiquismo, estes fatores certamente são causa necessária, mas não são suficientes para sozinhos engendrarem as organizações psíquicas atuais.

\section{Notas}

Roudinesco \& Plon (1997) ressaltam o fato de que, embora Haeckel seja o inventor das noções de ecologia, filogênese e ontogênese, na verdade, ele não é o autor da lei da recapitulação que lhe é geralmente atribuída. Na realidade, os prolegômenos desta lei são apresentados pelo próprio Darwin no capítulo XIII do A Origem das Espécies, cabendo a Haeckel o mérito de tê-la elaborado de modo mais aprofundado. 
2 Evidentemente, ao descrever estas formas psíquicas, a psicanálise as inventava dentro do plano de pensabilidade que era o seu. Para uma discussão sobre o assunto, cf. Winograd (1998).

3 No sentido de ter o caráter de um desenvolvimento natural, por oposição a um calculado e ideado (ex., fulano é um intelectual "orgânico"). Na carta a Fliess de 14 de novembro de 1897, Freud escreveu: "Muitas vezes, tive uma suspeita de que algo de orgânico desempenhava um papel no recalcamento [...]." (FREUD, 1986, p. 280).

4 "As neuroses possuem, de fato, sua função biológica, como um dispositivo protetor, e têm sua justificação social: a "vantagem da doença" que proporcionam não é sempre uma vantagem puramente subjetiva. Existe alguém entre os senhores que, alguma vez, não examinou a causalidade da neurose e não teve que admitir que esse era o resultado mais suave possível da situação?" (FREUD, 1993d, p. 135).

\section{REFERÊNCIAS}

FÉDIDA, P. La regresión: formes e déformations. In: FÉDIDA, P.; WIDLÖCHER, D. (Org.). Les evolutions: évolutions - phylogenèse de l'individuation. Paris: PUF, 1994.

FERENCZI, S. Thalassa: ensaio sobre a teoria da genitalidade. São Paulo: Martins Fontes, 1990.

. O desenvolvimento do sentido de realidade e seus estágios. In:

Obras completas: psicanálise II. São Paulo: Martins Fontes, 1992.

FREUD, S. A correspondência completa de S. Freud para W. Fliess. Rio de Janeiro: Imago, 1986.

. A phylogenetic fantasy: overview of the transference neuroses. Londres: The Belknap Press, 1987.

. De la historia de una neurosis infantil. In:

Sigmund Freud. Buenos Aires: Amorrotu, 1993a. v. 17.

Obras completas de

. El malestar en la cultura. In:

Buenos Aires: Amorrotu, 1993b. v. 21.

. La interpretación de los sueños. In:

Obras completas de Sigmund Freud.

Freud. Buenos Aires: Amorrotu, 1993c. v. 4 e 5.

La perturbación psicógena de la visión según el psicoanálisis. In: v. 12.

Obras completas de Sigmund Freud. Buenos Aires: Amorrotu, 1993d.

La repressión. In:

Aires: Amorrotu, 1993e. v. 14.

. Moisés y la religión monoteísta. In: . Obras completas de Sigmund Freud. Buenos

Freud. Buenos Aires: Amorrotu, 1993f. v. 23.

. Obras completas de Sigmund

. Totem y Tabu. In:

. Obras completas de Sigmund Freud. Buenos

Aires: Amorrotu, 1993g. v. 13.

. Tres ensayos de teoría sexual. In:

Freud. Buenos Aires: Amorrotu, 1993h. v. $\overline{7}$

. Obras completas de Sigmund 
GOULD, S. J. Ontogeny and phylogeny. Londres: The Belknap Press, 1977.

GUBRICH-SIMITIS, I. Prefácio. In: FREUD, S. A phylogenetic fantasy. Londres: The Belknap Press, 1987.

JACOB, F. A lógica da vida. Rio de Janeiro: Graal, 1983.

PINHEIRO, T. Ferenczi: do grito à palavra. Rio de Janeiro: J. Zahar, 1995.

PROCHIANZ, A. Formes et mémoires: vers une évolution expérimentale? In: FÉDIDA, P.; WIDLÖCHER, D. (Org.). Les evolutions: évolutions - phylogenèse de l'individuation. Paris: PUF, 1994.

RITVO, L. A influência de Darwin sobre Freud. Rio de Janeiro: Imago, 1992.

ROUDINESCO, E.; PLON, M. Dictionnaire de la Psychanalyse. Paris: Fayard, 1997.

SLAVIN, M. O.; KRIEGMAN, D. The adaptive design of the human psyche. New York: The Guilford Press, 1992.

SULLOWAY, F. J. Freud, biologist of the mind. Cambridge: Harvard University Press, 1979.

WINOGRAD, M. Genealogia do sujeito freudiano. Porto Alegre: Artes Médicas, 1998.

Recebido em: março/ 2005

Aceito em: outubro/ 2006 
